\title{
The 5-year strategy for ophthalmological research in the UK
}

R Hitchings

Eye (2002) 16, 685-686. doi:10.1038/

sj.eye. 0357

At the present time research and development funding for the UK's National Health Service (NHS) forms a major part of support for UK research. A recent report identified the support as $£ 400 \mathrm{~m}$ (approximately $\$ 600 \mathrm{~m}$ ) annually, of which $37.5 \%$ provides infrastructural support for externally funded peer reviewed projects. Funding from the NHS for eye research receives a small proportion $^{1}$ but this is in keeping with the number of projects listing 'Ophthalmology' on the National Research register (108 projects out of $12049^{2}$ ). Currently the value to the NHS of basic science research is being questioned because it is not seen to be clinically orientated, and may take years if not decades before the research results find their way into clinical practice.

Research in ophthalmology has suffered because research effort has been fragmented and ill thought out, and more importantly, parochial. As such it was often ineligible for, and unsuccessful in, obtaining major sponsorship. This failure has occurred despite visual loss being high on the list of patient concerns and responsible for considerable socio-economic disruption.

To redress this imbalance the Royal College of Ophthalmologists has set out to unify ophthalmic research in the UK. To do this the College first identified the major causes of blindness. Secondly, it divided these problems into clinical areas, and asked researchers in the UK, and patient support groups, for their views on both current problems in their area, and the research priorities needed to overcome them. These priorities ranged from 'blue skies' laboratory-based research, via clinical trials of new therapies, to health services research of tried techniques. These problems and 'solutions' were sent for an additional review outside the UK and then gathered together for publication as the
Colleges 5-year strategy for ophthalmological research in the UK. ${ }^{3}$

Where does this strategy take us? For the first time it has set out a national agenda for research in the UK. This sets an important example to other specialities in the UK, and to ophthalmology in many other countries, particularly those with similar problems. As a result, the College has been given affiliate status by the Department of Health Health Technology Assessment Programme (HTA) that gives the College a remit to suggest research questions for that organisation's support. Other sponsoring organisations are also looking at the document to help them set their research funding priorities. The document will guide the National Electronic Library for Eye Health (a web-based source of clinical and research information for lay readers and professional groups alike) and act as a template for the WHO Vision 20:20 project to combat global blindness. The strategy also allows co-ordination of eye research, by ensuring that 'blue skies' projects funded by the NHS are relevant to the needs of patients, and form part of comprehensive research programs, each targeted towards solving specific clinical problems.

Where does UK eye research go next? The document gives eye researchers priorities that are likely to receive support from funding organisations. It should stimulate more collaborative research between clinicians, and between clinicians and basic scientists. The Cochrane Eyes and Vision Group (CEVG), part of the Cochrane Initiative on Evidence Based Medicine, will support the research ideas, and their ability to identify the evidence base for treatments will in turn help formulate the most suitable research topic.

The College's 5-year research strategy should be seen as a unifying document for research in the UK, allowing the development of projects and programmes of work that can benefit the patient. Such a strategy will reverse the criticisms noted above and create
Moorfields Eye Hospital, City Road, London EC1V 2PD, UK

\section{Correspondence:} Professor R Hitchings Tel: 02075662818 Fax: 02076086925 E-mail: Roger.Hitchings@ Moorfields.nhs.uk 
the promise of better-funded eye research in the future. This in turn will allow more UK ophthalmologists to devote their career plans to research into the diseases they treat.

\section{References}

1 NHS Executive. Putting NHS Research on the Map. The Welcome Trust Publishing Dept, 2001.
2 The National Research Register. Department of Health Web site, June 2002

(hpp://www.update-software.com/national/).

3 The Royal College of Ophthalmology. A National Research Strategy for Ophthalmology. RCO: 2002. 